\title{
A importância da oralidade no ensino do Português
}

\section{Carla Sofia Lima Barreira Araújo}

Instituto Politécnico de Bragança - IPB - ESEB Centro de Estudos em Letras - CEL - UTAD, Bragança, Portugal, carla.araujo@ipb.pt

\begin{abstract}
Resumo
Por tradição, no contexto de ensino-aprendizagem da língua materna, verifica-se uma valorização do texto escrito, em detrimento do texto oral, indo de encontro à primazia do oral, que caracteriza as línguas naturais. Contrariando esta tendência, os Programas e metas curriculares de Português do Ensino Básico valorizam a oralidade, preconizando o oral como objeto de aprendizagem e um fim em si mesmo. A competência da oralidade constitui um fator determinante na promoção social dos indivíduos. Por conseguinte, perante o panorama de desafios atuais e futuros, na aula de Português do Ensino Básico, o professor deve pugnar pela produção de textos orais na norma-padrão do Português Europeu e estimular o espírito de rigor e de excelência, projetando o perfil de um falante autónomo, com a capacidade de utilizar a língua em todas as suas dimensões, em níveis de complexidade crescente e em conformidade com categorias e géneros específicos.
\end{abstract}

Palavras-chave: Oralidade; Ensino do Português; Língua Materna

\section{Introdução}

O presente artigo fundamenta-se nos referenciais teóricos da Linguística da Enunciação e tem como objetivo central promover um espaço de discussão sobre o ensino e as estratégias de operacionalização da oralidade na aula de Português do Ensino Básico.

Nesse sentido, procede-se a uma revisão da literatura de referência sobre esta problemática. Partindo dos conhecimentos disponibilizados pela investigação, procuraremos refletir sobre os seguintes pontos: o conceito de oralidade; a importância da oralidade nos Programas de Português do Ensino Básico; o desenvolvimento do domínio da oralidade em contexto pedagógico-didático. Este trabalho evidencia a extrema importância de desenvolver a competência oral dos alunos, de forma estruturada, sistemática e intencional, concorrendo, assim, para o desenvolvimento das suas competências linguísticas e comunicativas em Português. 


\section{Perspetivas sobre oralidade}

Como "Homo loquens" (Benveniste, 1966, p. 259), o Homem estabelece um vínculo estreitíssimo com a oralidade, já que, desde o instante em que é concebido, herda um património genético que lhe permitirá desenvolver essa modalidade de realização da língua, marca distintiva da espécie "Homo sapiens" a que pertence. Nesse sentido, Bakhtin (2000) afirma que não aprendemos a língua materna nos dicionários e nas gramáticas, ou seja, aprendemo-la "mediante enunciados concretos que ouvimos e reproduzimos durante a comunicação verbal viva que se efetua com os indivíduos que nos rodeiam" (p. 301).

Deste modo, de acordo com Bakhtin (2000), "a língua, a palavra, são quase tudo na vida do homem” (p. 346). Na sua práxis social, o Homem interage através da palavra, estabelecendo relações dialógicas que convocam a presença dos outros.

Embora a palavra não configure uma forma exclusiva de significação, Bakhtin (2002) destaca a "ubiquidade social da palavra" (p. 41). Esse dom de estar em toda a parte decorre do facto de a palavra ser também "interindividual" (Bakhtin, 2000, p. 350). No entanto, segundo Bakhtin (2002), "não basta colocar face a face dois homo sapiens quaisquer para que os signos se constituam. É fundamental que esses dois indivíduos estejam socialmente organizados, que formem um grupo (uma unidade social): só assim um sistema de signos pode constituir-se." (p.35).

$\mathrm{O}$ uso da língua opera-se através de sequências discursivas, resultantes de um ato de enunciação, ou seja, de enunciados. Os enunciados reproduzem as características e os objetivos de cada campo de ação das atividades humanas. Nesse sentido, Bakhtin (2000) define enunciado como "um todo historicamente individual e único, irreproduzível" (p. $357)$.

Considerando que, enquanto produto de um ato de enunciação, o enunciado pode ser oral ou escrito, este trabalho gira em torno do enunciado oral. Na sequência do que foi dito, levanta-se a seguinte questão: o que se entende por oralidade?

A escola, uma das instituições principais da sociedade, é a responsável pela adoção de uma visão "grafocêntrica da língua e da sua aprendizagem" (Silva et al., 2011, p. 7). Esta visão grafocêntrica contribui para "conceções redutoras e mesmo infundadas" (Amor, 2006, p. 64) da oralidade e da escrita. Demonstrando que o conceito de oral vai para além da distinção redutora e imprecisa que opõe as realizações orais, predominantemente coloquiais, às realizações escritas, que correspondem a um registo formal, a autora conclui que o modo de funcionamento comunicativo e as condições de produção "determinam as características (genéricas?) do modo oral; o modo de comunicação oral (como a leitura e a escrita) é cruzado por variáveis que conduzem à heterogeneidade dos processos/produtos 
comunicativos" (Amor, 2006, p. 64). Por conseguinte, os fenómenos da oralidade devem ser analisados tendo em consideração um enquadramento comunicativo.

Atendendo ao facto de que, do ponto de vista pedagógico, na abordagem ao oral/escrito, deve valorizar-se uma perspetiva contrastiva, Amor (2006, p. 64-65), associando as palavras "efemeridade" e "permanência" aos modos oral e escrito, respetivamente, destaca cinco traços distintivos:

1) Dependência contextual

2) Planificação, controle

3) Manobras de reforço e correção

4) Prescrições formais, normalização

5) Distância

Assim, a autora resume os principais traços diferenciadores do oral e do escrito, na seguinte esquematização (ver Quadro 1):

Quadro 1 - Oral/escrito - principais traços diferenciadores

\begin{tabular}{|c|c|c|c|c|}
\hline \multicolumn{3}{|c|}{ ORAL } & - & \\
\hline \multirow{2}{*}{} & + & Dependência contextual & \\
\cline { 2 - 4 } & - & Planificação, controle & + \\
\cline { 2 - 4 } & + & Manobras de reforço e correção & - \\
\cline { 2 - 5 } & - & Prescrições formais, normalização & + \\
\cline { 2 - 5 } & - & Distância & + \\
\cline { 2 - 5 } & & & \\
\hline
\end{tabular}

De igual modo, a nomenclatura oficial do português para efeitos escolares, patente no Dicionário Terminológico, publicado pela portaria 476, de 18 de Abril de 2007 e acessível on-line em http://dt.dgidc.min-edu.pt, em C.1.1. (subdomínio comunicação e interação discursivas), apresenta uma definição de oralidade que vai ao encontro da anteriormente apresentada, acrescentando o facto de a oralidade ser o "modo primário, natural e universal da realização da língua".

\section{A didática da oralidade}

Amor (2006), realçando o vínculo estreito que une o uso da língua e o saber cultural, realça que o discurso oral é uma construção coletiva, o resultado de uma coenunciação. Por conseguinte, o desenvolvimento da competência oral dos alunos exige que, na aula de Português, "se criem momentos e condições para o exercício da palavra com propósitos 
diversificados, o que significa também o respeito e a atenção à palavra do outro: a aprendizagem da oralidade é, assim, a aprendizagem do social, por excelência" (Amor, 2006, pp. 65-66). Nesta linha de pensamento, Figueiredo (2011) entende que "num contexto de comunicação oral, o reconhecimento dos mundos de referência passa pela capacidade de inserção de uma gramática de base oracional numa gramática do discurso adequando-se, por esta via, o texto ao contexto" (p. 249).

Deste modo, a autora reconhece que a separação dos conhecimentos nos níveis estratégico (contexto), discursivo (discurso) e formal (formas linguísticas), pedagogicamente, pode trazer problemas, devido ao facto de ser difícil delimitar as fronteiras entre o "estudo da língua como texto-discurso e o estudo da língua como sistema formal” (Figueiredo, 2011, p. 250).

A autora prossegue e defende que "tal distinção conceptual é pedagogicamente necessária, mesmo faltando uma referência teórica que ofereça uma descrição funcional completa para a sua utilização pedagógica" (Figueiredo, 2011, p. 250). Uma vez que é impossível o uso da língua isento de qualquer género de atividade metalinguística, para Figueiredo (2011), é fundamental que o ensino da gramática implique a aquisição de conceitos e de terminologia que viabilizem a interação entre reflaxão e uso.

Deste modo, Figueiredo (2011, p. 251), considerando o discurso como ato de comunicação, aponta as vertentes da "gramática da língua oral": competência linguística, competência enciclopédica, competência retórico-pragmática e competência lógica.

Fundamentando-se no pensamento do psicolinguista J. P. Bronckart, Figueiredo (2011, p. 262) sustenta que a didática do oral deve conferir primazia à recontextualização das formas linguísticas no discurso. Uma vez que a aquisição das formas linguísticas se processa de forma demorada e que o "domínio dos usos quotidianos do ponto de vista discursivofuncional só começa a alcançar-se a partir dos dez ou doze anos, a escola deverá, o mais cedo possível, trabalhar com os seus alunos textos orais em interação" (Figueiredo, 2011, p. 262).

O trabalho a incrementar no âmbito da oralidade deve desenvolver as microhabilidades (Cassany et al., 2000) pertencentes à compreensão do oral: reconhecer, selecionar, interpretar, antecipar, inferir e reter. Nesse sentido, os alunos devem ter consciência de que os mecanismos cognitivos subjacentes ao discurso oral diferem dos mecanismos cognitivos inerentes ao discurso escrito, quer no âmbito da expressão quer no âmbito da compreensão (Duarte et al., 2009). 


\section{A importância da oralidade nos Programas de Português do Ensino Básico}

A análise diacrónica dos Programas de Língua Portuguesa/Português, desde 1921 até 2001, efetuada por Duarte et al. (2008), permite-nos constatar que o domínio da oralidade esteve sempre presente nos documentos orientadores do ensino da Língua Portuguesa, tendo sido enquadrado pelos respetivos paradigmas de ensino da língua materna vigentes no contexto histórico de emissão dos mesmos. Segundo os mesmos autores, os textos programáticos de 1960, cujo objetivo consiste em "coordenar e atualizar as matérias do ensino primário" (Duarte et al., 2008, p. 22), operam uma transformação que permitirá romper com o "paradigma académico, que remonta ao século XIX e que perspetiva a língua como "língua escrita" (Duarte et al., 2008, p. 24). Todavia, apenas, em 1979, se concretiza a mudança antecipada pelo programa de 1960.

Embora se vá conferindo uma certa relevância ao domínio da oralidade, mas apenas no ensino secundário, uma vez que "a partir da análise de textos dever-se-á incentivar, entre outras, a comunicação por via oral e o debate" (Duarte et al., 2008, p. 25).

Com efeito, o Programa de Português do Ensino Secundário, de 1991, tem como objetivo "assegurar o desenvolvimento integrado das competências comunicativas e linguísticas, sempre a partir de situações de uso e tendo em vista o melhoramento, correção ou desenvolvimento da própria competência comunicativa" (Duarte et al., 2008, p. 23). No entanto, segundo os mesmos autores, o domínio ouvir/falar possui um peso relativo claramente inferior, relativamente aos domínios do ler e do escrever. A projeção conferida à competência da oralidade decorre do "paradigma comunicativo, que influenciará, juntamente com o utilitário, os textos programáticos da década de 90.” (Duarte et al., 2008, p. 25).

No Ensino Básico, a consumação do percurso de autonomização da oralidade apenas se verifica no Currículo Nacional do Ensino Básico, de 2001, onde surge como "competência autónoma, subdividindo-se em compreensão oral e expressão oral" (Duarte et al., 2008, p. 25).

Os documentos orientadores do ensino da Língua Portuguesa para o Ensino Básico revelam que, por tradição, no contexto de ensino-aprendizagem da língua materna, verifica-se uma valorização do texto escrito, em detrimento do texto oral, indo de encontro à primazia do oral, que caracteriza as línguas naturais. Contrariando essa tendência grafocêntrica, os atuais Programas e metas curriculares de Português do Ensino Básico (Buescu et al., 2015) valorizam a oralidade, preconizando o oral como objeto de aprendizagem e um fim em si mesmo. Tal valorização da oralidade implica, do ponto de vista didático, por um lado, a responsabilidade do professor de Português de ensinar explicitamente "estratégias de escuta ativa com vista a reter informação essencial, a desenvolver a compreensão, e a produzir enunciados orais em contextos específicos" (Buescu et al., 2015, p. 5) e, por outro 
lado, "a exercitação por parte do aluno" (Buescu et al., 2015, p. 5), tendo em vista uma aprendizagem consistente.

Segundo Silva et al. (2011, p. 17), “a insistência no trabalho explícito sobre as competências orais (e, consequentemente, sobre a sua avaliação) constitui uma relativa novidade no ensino do Português". De facto, os Programas e metas curriculares de Português do Ensino Básico (Buescu et al., 2015) enfatizam o domínio de referência da Oralidade, o que se pode constatar, desde logo, nos objetivos do documento regulador (Buescu et al., 2015, p. 5-6): dos 21 objetivos apresentados, 10 remetem diretamente para a oralidade (objetivos 1, 2, 3, 4, 7, 13, 14, 18, 19 e 21).

No início do 1. ${ }^{\circ}$ Ciclo do Ensino Básico, uma vez que a escrita constitui uma representação da linguagem oral, os conteúdos do domínio de referência da Leitura e Escrita encontramse intimamente relacionados. Essa interação entre domínios verifica-se também ao nível da Gramática (Buescu et al., 2015, p. 8).

Para o 2. ${ }^{\circ}$ Ciclo do Ensino Básico, preconiza-se que os alunos, no final do mesmo, possuam um "conhecimento reflexivo e explícito das regras gerais da língua e das suas ocorrências mais frequentes, e apliquem esse conhecimento fazendo um bom uso do português nas diversas situações de oralidade" (Buescu et al., 2015, p. 20). Nesse sentido, espera-se que, no domínio da Oralidade, os alunos apresentem desempenhos que "revelem o respeito, já constituído como rotina, pelos princípios de cortesia e de cooperação no plano da interação verbal" (Buescu et al., 2015, p. 19). Neste ciclo, espera-se também que "quer a compreensão do oral quer a expressão oral ganhem maior dimensão e formalidade" (Buescu et al., 2015, p. 19). Tendo em vista estes objetivos, quer em relação à compreensão do oral quer relativamente à expressão oral, verifica-se uma "diversificação dos textos orais a trabalhar e uma complexificação das tarefas solicitadas a propósito desses textos [...], inicia-se ainda a autonomização do discurso argumentativo, com vista a um trabalho cuja formalização prosseguirá no 3. ${ }^{\circ}$ Ciclo e no Ensino Secundário" (Buescu et al., 2015, p. 19).

Reforçando o ensino formal e a prática das capacidades de produção e compreensão orais, no 3. ${ }^{\circ}$ Ciclo do Ensino Básico, no domínio da Oralidade, atribui-se especial importância "à organização, ao registo e à planificação da informação, bem como à capacidade de realização de inferências [...]. Destaque ainda [...] para o desenvolvimento do estudo dos textos de características expositivas e argumentativas" (Buescu et al., 2015, p. 27). Por conseguinte, pretende-se que os alunos, no final do 3. ${ }^{\circ}$ Ciclo do Ensino Básico, "tenham capacidade de utilizar, oralmente e por escrito, passiva e ativamente, os recursos linguísticos, fazendo um uso sustentado do português padrão nos diferentes contextos discursivos e sociais em que é utilizado.” (Buescu et al., 2015, p. 28).

Atualmente, decisores políticos, estudiosos e investigadores estão de acordo quanto à necessidade de adotar formas de escolarização e de organização escolar renovadas. Com 
efeito, unanimemente, reconhece-se que cabe à escola cumprir uma função primordial, em todos os níveis de educação e ciclos de ensino, isto é, a escola deve garantir a "aquisição de conhecimentos, o desenvolvimento de capacidades [...] que permitam às crianças e aos jovens a compreensão crítica e a participação informada perante desafios locais e globais que se colocam à construção de um mundo mais justo, inclusivo e solidário" (Torres et al., 2016, p. 5).

Neste sentido, no mundo atual, em constante e imprevisível transformação, a escola assume um papel que vai para além do ensino, ou seja, "a escola do século 21 [...] mais do que ensinar, deve apoiar os alunos na construção de uma bússola confiável e no desenvolvimento de habilidades para que [os alunos] possam identificar caminhos possíveis" (Fadel et al., 2015, p. 9). De facto, a incerteza, transitoriedade e instabilidade dos tempos que correm exigem a renovação dos contextos de aprendizagem, de modo a desenvolver nos alunos competências que lhes permitam encarar, com firmeza, as céleres mutações sociais e económicas com que se depararão no futuro.

Deste modo, perante o panorama de desafios atuais e futuros, na aula de Português do Ensino Básico, o professor deve pugnar pelo conhecimento da norma-padrão do Português Europeu e estimular o espírito de rigor e de excelência, projetando "o perfil de um falante e de um escrevente autónomo na utilização multifuncional e cultural da língua, capaz de progredir para outros graus de ensino" (Buescu et al., 2015, p. 3).

\section{Desenvolvimento do domínio da oralidade em contexto pedagógico-didático}

Amor (2006), rejeitando o monologismo que caracteriza o diálogo pedagógico, defende "a transformação do modelo de comunicação da aula como condição do alargamento do potencial comunicativo do aluno" (p. 68), dado que o uso comunicativo da língua permite o desenvolvimento de competências linguísticas. A mesma autora, concordando com o truísmo "aprende-se a falar, falando", recomenda que se disponibilize mais tempo para a palavra ser tomada por todos os alunos, em conformidade com as suas competências.

Nesse sentido, concordamos com Silva et al. (2011, p. 12), que defendem um "trabalho efetivo sobre as competências orais com a sustentação teórica e metodológica que retire as atividades realizadas nesse campo do nível das meras intuições, do improviso ou do trabalho avulso ou desestruturado".

Por conseguinte, tendo em vista o desenvolvimento das competências orais dos alunos, Silva et al. (2011, p. 17-23) destacam cinco dimensões a trabalhar na aula de Português: 1) competências articulatórias; 2) competências prosódicas; 3) competências pragmáticodiscursivas; 4) consciência explícita de fenómenos de variação linguística a nível das estruturas fonético-fonológicas da língua; 5) planeamento de produções linguísticas. 
No trabalho de treino das competências articulatórias, os textos de carácter lúdico, nos quais, em alguns casos, o significante suplanta o significado (rimas infantis; lengalengas e trava-línguas;), configuram um recurso didático profícuo, que permite, conforme sugerem Silva et al. (2011, p. 18), um "trabalho a outros níveis (recursos estilísticos, vocabulário, funcionamento da língua) ". Neste âmbito, é igualmente importante a produção oral de enunciados poéticos, recorrendo a aliterações, onomatopeias, bem como a realização de jogos orais de palavras, levando os alunos a produzir rimas a partir de palavras ditas por outros colegas, formar novas palavras, através de adição, supressão ou modificação da posição de sílabas, etc.

A operacionalização de um trabalho centrado no aperfeiçoamento das competências prosódicas implica os alunos na prática de uma articulação cuidada, devidamente planeada e inteligível, convocando o conhecimento dos planos fónico e gráfico da estrutura da língua, consciencializando-os do papel fundamental que a entoação assume ao nível da frase e na expressão de diferentes emoções (Silva et al., 2011, p. 36-45).

No mesmo sentido aponta Lopes (2011), defendendo que a compreensão e expressão orais exigem, inquestionavelmente, que o aluno seja capaz de produzir bem como interpretar uma multiplicidade de enunciados que possuem finalidades e funções comunicativas diversas. Por conseguinte, o espaço pedagógico de desenvolvimento da oralidade envolve a performatividade generalizada da língua em uso. Assim, a mesma autora faz referência às curvas de entoação "suporte prosódico fulcral na construção dos diferentes atos de fala" (Lopes, 2011, p. 226).

No que respeita ao desenvolvimento de competências pragmático-discursivas, o treino do domínio oral exige a realização de exercícios quer do nível linguístico, como por exemplo, de nível fónico, de nível gramatical e de nível lexical, quer do nível comunicativo, considerando a importância do contexto, a relação interpessoal existente entre os interlocutores, bem como os princípios reguladores da interação discursiva.

Lopes (2011), preconizando que a aula de Português é "um espaço de práticas de e sobre a língua" (p. 229), considera que "competência gramatical e competência pragmática são componentes complementares para um desempenho discursivo proficiente num leque alargado de situações sociais" (Lopes, 2011, p. 225). A mesma autora sublinha que a consideração dos atos de fala, observando a sua formulação direta e indireta, "convoca necessariamente um enquadramento sócio-psicológico da comunicação linguística, permitindo trabalhar na prática diversas estratégias discursivas de cortesia, cujo domínio contribui seguramente para o sucesso escolar e social dos alunos" (Lopes, 2011, p. 226).

De igual modo, em contexto pedagógico-didático, deverão ser trabalhados os recursos paralinguísticos, cinésicos e proxémicos, uma vez que têm uma grande importância no discurso oral e revelam a enorme implicação que os contextos extra-verbais representam 
neste âmbito. Atendendo ao facto de que a opção por um género discursivo oral condiciona a estratégia comunicativa a seguir, bem como as opções linguísticas, quer em atividades de produção quer em tarefas de compreensão orais, deve relevar-se as especificidades de cada género discursivo oral, de acordo com parâmetros como o grau alto/baixo de formalidade, o posicionamento dos participantes e o papel do alocutário (Silva et al., 2011, p. 20-22).

Relativamente à dimensão da consciência explícita de fenómenos de variação linguística a nível das estruturas fonético-fonológicas da língua, Silva et al. (2011) recomendam atividades que girem em torno de duas vertentes fulcrais, ou seja, "a inexistência de línguas sem variação e o combate ao preconceito social existente a respeito de algumas manifestações de variação linguística" (p. 23).

Lopes (2011) sustenta que o Professor não pode ignorar a diversidade linguística dos alunos e o facto de "muitas crianças iniciarem a escolaridade básica sem um efetivo domínio da variedade padrão do Português" (p. 225). Por isso, é missão da escola, e mais especificamente da aula de Português, "promover o domínio desta variedade por parte de todos os alunos" (p. 225).

No que concerne ao planeamento de produções linguísticas, Silva et al. (2011), enfatizando que o discurso oral se pauta pelas mesmas regras do discurso escrito formal, em termos de planeamento, organização e estruturação, lembram que, na fase de planeamento e realização da expressão oral, o professor deve destacar essa caraterística "contribuindo-se assim para o afastamento da ideia de que a expressão oral se caracteriza obrigatoriamente pelo improviso e pela falta de coerência" (p. 23).

Como se refere em (Duarte et al., 2009, p. 57), a oralidade é uma atividade que se cruza inevitavelmente com a escrita: "a exposição oral deveria ser uma prática que contribuísse para a consolidação da linguagem e que preparasse por consequência uma passagem à escrita sem hesitação" (Duarte et al., 2009, p. 57).

Como sustenta Duarte et al. (2009), todas as atividades orais devem provocar nos alunos o entusiasmo pela aprendizagem da língua, por isso, "crie-se no aprendente prazer em mexer nas peças que constituem a linguagem [e] confira-se ao aprendente a possibilidade de se exprimir com facilidade em diferentes domínios" (Duarte et al., 2009, p. 58).

Desta forma, o professor de Português deve fazer um investimento firme na oralidade, cabendo-lhe "a tarefa de acompanhar o desenvolvimento da linguagem dos seus alunos tirando partido tanto de textos dos mais diversos tipos de forma e de conteúdo como das mais variadas situações de discurso oral" (Duarte et al., 2009, p. 86).

Assim, compete ao Professor de Português a estimulante tarefa de orientar o processo de ensino e aprendizagem da oralidade de acordo com as especificidades dos seus alunos. 


\section{Considerações finais}

A competência da oralidade constitui um fator determinante na promoção social dos indivíduos. Por conseguinte, perante o panorama de desafios atuais e futuros, na aula de Português do Ensino Básico, o professor deve pugnar pela produção de textos orais na norma-padrão do Português Europeu e estimular o espírito de rigor e de excelência, projetando o perfil de um falante autónomo, com a capacidade de utilizar a língua em todas as suas dimensões, em níveis de complexidade crescente e em conformidade com categorias e géneros específicos.

Com este trabalho, esperamos ter contribuído para evidenciar a extrema importância de desenvolver a competência oral dos alunos, de forma estruturada, sistemática e intencional, concorrendo, assim, para o desenvolvimento das suas competências linguísticas e comunicativas em Português.

\section{Referências}

Amor, E. (2006). Comunicação e expressão oral. In: AMOR, E. Didática do Português fundamentos e metodologia. Lisboa: Texto Editores, 2006, p. 61-81.

Bakhtin, M. (2000). Estética da Criação Verbal. Trad. de Maria E. G. G. Pereira. São Paulo: Martins Fontes.

Bakhtin, M. (2002). Marxismo e Filosofia da Linguagem. Trad. de Michel Lahud e Yara Frateschi Vieira. São Paulo: Hucitec/Annablume.

Benveniste, E. (1966). Problèmes de Linguistique Générale. Paris: Gallimard. Vol. I.

Buescu, H., C. et al. (2015). Programas e metas curriculares de Português do Ensino Básico. Lisboa: Ministério da Educação e Ciência.

Cassany, D., Luna, M. \& Sanz, G. (2000). Enseñar lengua. Barcelona: Graó.

Duarte, I. M., Figueiredo, O. \& Veloso, J. (Eds. 2009). A linguagem ao vivo. Textos selecionados de Maria da Graça L. Castro Pinto. Porto: Faculdade de Letras da Universidade do Porto.

Duarte, R., Veigas, A. S., Batalha, J., Pignatelli, M. L., Henriques, M. (2008). Programa de Língua Portuguesa/Português: uma visão diacrónica. Lisboa: Ministério da Educação Direção Geral de Inovação e de Desenvolvimento Curricular.

Fadel, Ch. et al. (2015). Educação em quatro dimensões: As competências que os alunos devem ter para atingir o sucesso. Center for Curriculum Redesign. Boston, MA. http://www.institutoayrtonsenna.org.br/arquivos/Educacao-em-quatro-dimensoes.pdf (consultado em maio de 2018). 
Figueiredo, O. (2011). Da Língua como sistema à fala como ato. Ensino do modo oral. In: DUARTE, I.M. e O. Figueiredo (org.). Português, Língua e Ensino. Porto: Universidade do Porto, 2011, p. 247-265.

Lopes, A. C. M. (2011). Actos de fala e ensino do Português como língua materna: algumas reflexões. In: DUARTE, I. M. e O. Figueiredo (org.) Português, Língua e Ensino. Porto: Universidade do Porto, 2011, p. 223-246.

Silva, F., Viegas, F., Duarte, I. M. \& Veloso, J. (2011). Guião de Implementação do Programa: Oralidade. Lisboa: Ministério da Educação.

Torres, et al. (2016). Referencial de Educação para o Desenvolvimento - Educação Pré-Escolar, Ensino Básico e Ensino Secundário. Ministério da Educação. 